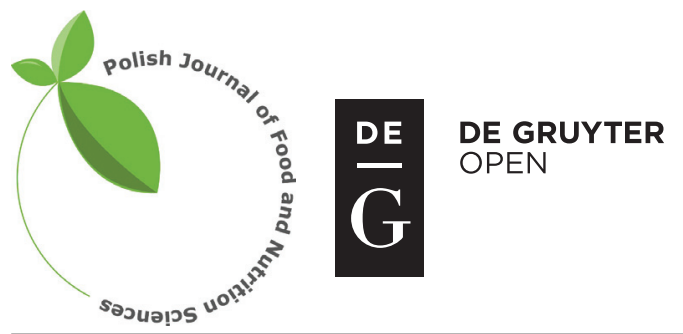

Pol. J. Food Nutr. Sci., 2018, Vol. 68, No. 1, pp. 83-90 DOI: $10.1515 /$ pjfns-2017-0010 http://journal.pan.olsztyn.pl

Original research article

Section: Food Quality and Functionality

\title{
Antioxidative Effects of Phenolic Compounds of Mushroom Mycelia in Simulated Regions of the Human Colon, In Vitro Study
}

\author{
Emanuel Vamanu ${ }^{1 *}$, Diana Pelinescu², Ionela Avram ${ }^{2}$ \\ ${ }^{1}$ University of Agronomic Science and Veterinary Medicine - Faculty of Biotechnology, \\ 59 Marasti blvd, 1 district, 011464, Bucharest, Romania \\ ${ }^{2}$ MICROGEN - Center for Research in Microbiology, Genetics and Biotechnology, \\ University of Bucharest, Faculty of Biology, 1-3 Portocalilor Str., 5 district, 060101, Bucharest, Romania
}

Key words: antioxidant, gentisic acid, GIS1 system, microbiota, mycelia, Pleurotus ostreatus

Many compounds in mushrooms are biologically active; however, the in vivo actions of their metabolites are poorly understood. An in vitro system, GIS1, was used to simulate the fermentation action of microbiota in each colon region. We used MycoPo, a natural product obtained from the lyophilized mycelia of different Pleurotus ostreatus species to determine the biological effects in human-colon regions. Controls (Lentinula edodes mycelia; dried basidia of Agaricus brunnescens) were chosen to confirm the biological activity of $P$. ostreatus mycelia in vitro. We measured total antioxidant capacity and ferric ion-reducing antioxidant power (FRAP) in simulated colon regions to identify antioxidant compounds, and undertook in vitro gastrointestinal simulation and microbiological analyses. The highest FRAP was found for the ascending colon, and the antioxidant effect was higher when MycoPo was administered. A. brunnescens consumption resulted in low total antioxidant capacity. Polyphenol content was correlated with the antioxidant status and microbial composition of microbiota. Total polyphenolic content was higher after $A$. brunnescens consumption, and four types of polyphenols were identified by high-performance liquid chromatography. Major phenolic acids were gentisic acid, homogentisic acid, and small amounts of caffeic acid. The Enterobacteriaceae species populations varied greatly across the three parts of the colon. We noted a significant $(\mathrm{p}<0.01)$ correlation between antioxidant status in the transverse and descending colon after MycoPo administration, and A. brunnescens consumption with the number of Lactobacillus and Bifidobacteria species $\left(R^{2}>0.85\right)$. These data suggest a direct relationship between favorable bacterial strains and availability of bioactive compounds, with specificity for each colon region.

\section{INTRODUCTION}

The pharmacological and biological activities of mushroom mycelia are well known [Lindequist et al., 2005]. Immunomodulatory properties of such mycelia can be elicited because of the polyphenolic carboxylic acids, tocopherols, and polysaccharides contained within them [Jeong et al., 2013]. Mushroom species release various active compounds that can be controlled by physical and chemical factors during fermentation [Elisashvili, 2012]. Interest in mushrooms is also derived from the limited use of this natural resource, especially in "phytomedicine" [Ekor, 2014].

Products obtained from dried sporocarps (multicellular structures on which spore-producing structures are borne) or by fermentation are usually employed as supplements due to their cholesterol reduction, antioxidant, anti-tumor [Lindequist et al., 2005], immunomodulatory [Wasser, 2014], and antimicrobial properties [Elisashvili, 2012]. Pleurotus species and Lentinula edodes have specific health effects on microbiota because they contain glucans, mannans, and xylans. These bioactive compounds improve nutrient presence in the colon, which has a positive effect on the fermentation capacity of mi-

\footnotetext{
* Corresponding Author: E-mail: email@emanuelvamanu.ro (E. Vamanu)

crobiota [Din et al., 2012]. New compounds (e.g., rosmarinic acid) have been identified in the extracts of sporocarps of $B O-$ letus edulis collected from Romanian forests. However, rosmarinic acid was not identified after consumption of $B$. edulis because digestion alters the structures of certain bioactive compounds. This phenomenon has been demonstrated using a unicameral system of gastrointestinal simulation called "GIS1" (www.gissystems.ro) [Vamanu et al., 2012, 2013]. This in vitro system allows simulation of the fermentation action of microbiota in each region of the colon based on retention time and $\mathrm{pH}$. Results have been comparable with those of complex systems, including dynamic ones such as the Simulator of Human Intestinal Microbial Ecosystem (www.prodigest.eu).

Microbial composition varies along the digestive tract. Also, fermentation processes are different in each part of the intestine [Conlon \& Bird, 2015]. In the upper region of the colon, synthesis of organic acids occurs, which can be useful for inhibition of pathogenic strains [Kailasapathy \& Chin, 2000]. In the lower part of the colon, once the sources of readily fermentable carbon have been exhausted, synthesis of metabolites considered to be toxic (e.g., ammonia, sulfur compounds) occurs. This phenomenon is a major cause of different diseases, of which the most serious is colon cancer 
[Hughes et al., 2000]. Hamer and colleagues stated that reduction of synthesis of short-chain fatty acids (especially butyrate) hampers the capacity to fight oxidative stress [Hamer et al.,2008]. Thus, the availability of compounds with antioxidant effects gradually freed as a result of the fermentation action of microbiota has an important role in lowering the prevalence of acute and tumor-related inflammatory processes. The presence of certain phenolic compounds (especially, gentisic and homogentisic acids and catechin) was correlated with the number of lactic acid bacteria strains, in in vitro tests [Vamanu et al., 2013].

Most studies have focused on the improvement of production of metabolites and/or mycelium amount through fermentation [Lee et al., 2004] and the value of the final products [Chen et al., 2012], but in vivo actions are poorly understood. The absorption capacity of the main biologically-active compounds is dependent upon the: (i) method used for preparation of the product; (ii) microbial composition from the gastrointestinal tract [Manach et al., 2004]. In this situation, activation of some molecules is carried out by microbiota in the gastrointestinal tract. Some of these active molecules are inactivated during fermentation processes by microbial strains or by stress factors from the digestive tract [van de Heijning et al., 2014]. "MycoPo" is a natural product obtained from the lyophilized mycelia of different species of $P$. ostreatus and formulated to test the biological effects on parts of the human colon. MycoPo is obtained exclusively from the mycelia of Pleurotus species, so does not include dried sporocarps. Microbiota presence is correlated directly with gastrointestinal motility, so MycoPo is expected to improve the action of microbial strains because only the mycelia of Pleurotus species are used [Choi \& Chang, 2015]. The present study is an improvement over previous works because potential inhibitory compounds from dried sporocarps were eliminated. The aim of our study was to determine the total antioxidant activity and identify antioxidant molecules in relation to the number of favorable bacterial strains in human microbiota by in vitro simulation of the human gastrointestinal tract using the GIS1 system.

\section{MATERIALS AND METHODS}

\section{Materials}

Mycelia of three strains of P. ostreatus (PQMZ91109, PBS281009, PSI101109) were isolated from mushrooms from Băneasa forest (Bucharest, Romania). Mycelia from P. ostreatus M 2191 were obtained from Mycelia BVBA (a mushroom-spawn laboratory and spawn-production training center situated in Nevele, Belgium). Two controls were used: mycelia from Lentinula edodes FP0213 (obtained from the collection of the Faculty of Biotechnology, Bucharest) and dried basidia of Agaricus brunnescens (purchased from a supermarket in Graz, Austria). Controls were chosen to confirm the biological activity of $P$. ostreatus mycelia in vitro.

Mycelia were preserved at $-80^{\circ} \mathrm{C}$ and revitalized on potato dextrose agar medium at $4^{\circ} \mathrm{C}$. The first inoculum was prepared by growing mushrooms on a rotary shaker (LabTech, Tampa, FL, USA) at $150 \mathrm{rpm}$ for 5 days at $25^{\circ} \mathrm{C}$ in $500-\mathrm{mL}$ Erlenmeyer flasks containing $250 \mathrm{~mL}$ of the synthetic medium (in $\mathrm{g} / \mathrm{L}$ : glucose, 6.0; malt extract, 100.0; yeast extract, 20.0; $\left.\mathrm{KH}_{2} \mathrm{PO}_{4}, 1.0 ; \mathrm{MgSO}_{4} \times 7 \mathrm{H}_{2} \mathrm{O}, 0.5\right)$. The medium was adjusted to a pH of 5.5 with $0.2 \mathrm{~mol} / \mathrm{L} \mathrm{NaOH}$ [Vamanu, 2012].

The second inoculum was prepared in a $500-\mathrm{mL}$ flask containing $300 \mathrm{~mL}$ of the medium after inoculation with $10 \%$ $(v / v)$ of the first-inoculum culture under the conditions described above. The fermentation medium $\left(\mathrm{KH}_{2} \mathrm{PO}_{4}, 0.2 \%\right.$; $\left.\mathrm{CaSO}_{4}, 0.5 \% ; \mathrm{MgSO}_{4}, 0.05 \% ; \mathrm{Na}_{2} \mathrm{HPO}_{4}, 0.01 \%\right)$ was inoculated with the second-inoculum culture $(10 \% v / v)$ and then cultivated in a 5-L New Brunswick ${ }^{\mathrm{TM}}$ BioFlo $^{\mathrm{TM}} 310$ Bioreactor (Eppendorf, Hamburg, Germany). Fermentations were conducted at $25^{\circ} \mathrm{C}$ at an aeration rate of $1 \mathrm{vvm}$, agitation speed of $150 \mathrm{rpm}, \mathrm{pH}$ of 5.5-6, and working volume of $4 \mathrm{~L}$. The inoculum culture was transferred to the fermentation medium and cultivated for further 10 days [Vamanu, 2012].

Mycelia were recovered from the liquid medium by centrifugation at $4000 \times g$ for $15 \mathrm{~min}$ at room temperature. Next, mycelia were washed thrice with distilled water and freeze-dried in a freeze-dryer (Alpha 1-2 LD; Martin Christ, Osterode am Harz, Germany) in the absence of a cryoprotective agent. The "MycoPo product" (name chosen by authors to be relevant to the composition) comprised a freeze-dried biomass of all $P$. ostreatus species at a ratio of 1:1:1:1 in gastro-resistant capsules. Mycelia from L. edodes and dried basidia of $A$. brunnescens were crushed with a laboratory knife mill (Grindomix GM 200; Retsch, Haan, Germany) and processed under identical conditions. Mycelia of the tested mushrooms were embedded in enterosoluble capsules, which were filled with a manual capsule filling machine 00 size.

\section{Determination of total antioxidant capacity in simulated colon regions}

Ferric ion-reducing antioxidant power (FRAP) assay

To $3 \mathrm{~mL}$ of FRAP reagent there was added $0.3 \mathrm{~mL}$ of ultrapure water. Samples $(100 \mu \mathrm{L})$ were taken and $96 \%$ ethanol was added to make a final volume of $3.4 \mathrm{~mL}$. Absorbance at $595 \mathrm{~nm}$ was read against a reagent blank at the end of $6 \mathrm{~min}$, and correlated with the Trolox-equivalent antioxidant capacity of the mycelium [Alpinar et al., 2009; Ozyurek et al., 2012]. The sample consisted of a liquid resulting from in vitro simulation, without microbial cells or other mushroom wastes. The control was represented by the activity determined before administration of the food supplement/product (after microbiota restoration process).

\section{Total antioxidant activity}

The total antioxidant activity of samples was measured using the 2,2'-azino-bis(3-ethylbenzothiazoline-6-sulfonic acid, ABTS) radical cation and expressed as equivalents of ascorbic acid (mmol/mL) [Diwan et al., 2012; Vamanu et al., 2013]. The control was represented by the activity determined before administration of the food supplement/product.

\section{Determination of antioxidant compounds}

Total soluble phenolic content was estimated using the Folin-Ciocalteu method. Total soluble flavonoid content was estimated by the aluminum chloride colorimetric method [Premanath et al., 2011; Vamanu et al., 2013]. 
Determination of polyphenol carboxylic acids, flavones, and tocopherols was done by high-performance liquid chromatography (HPLC) as described previously [Vamanu et al., 2013].

\section{In vitro gastrointestinal simulation}

\section{Protocol for in vitro digestion}

Dried mushrooms (20 g) were mixed with $10 \mathrm{~mL}$ of $\mathrm{NaCl}$ $(0.9 \%)$ and simulated gastric solution $(3 \mathrm{~mL}$ pepsin $(40 \mathrm{mg} / \mathrm{mL})$, pH 2 adjusted with $\mathrm{HCl}(0.1 \mathrm{~N})$ ). In vitro digestion occurred within the GIS1 system during phase-1, at physiological temperature $\left(37^{\circ} \mathrm{C}\right)$. The mixture was maintained at the specified $\mathrm{pH}$ for $\approx 2 \mathrm{~h}$ with slow, continuous shaking. For the small-intestine phase, the $\mathrm{pH}$ was adjusted to 5.4 with $\mathrm{Na}_{2} \mathrm{CO}_{3}(1 \mathrm{~mol})$, and then $9 \mathrm{~mL}$ pancreatin $(2 \mathrm{mg} / \mathrm{mL})$ and bile salts $(3 \mathrm{mg} / \mathrm{mL})$ were added to maintain the mixture under the conditions mentioned above for $2 \mathrm{~h}$. Finally, parts of digested fungi were stored for introduction to phase-2 of the colon simulation system GIS1 [Green et al., 2007; Vamanu et al., 2013].

\section{Simulation of the human colon in vitro}

Conditions within the colon were replicated in a single-chamber system (GIS1) inoculated with 10\% (wt/v) homogenized feces (from a 4-year-old healthy child) in peptone water with introduction of $1 \%(\mathrm{wt} / \mathrm{v})$ mushrooms into the digestion process. After inoculation, GIS1 was left for $\approx 24 \mathrm{~h}$ of continuous fermentation for microbiota stabilization. The system was operated for minimum $20 \mathrm{~h}$ [Tzortzis et al., 2005]. The GIS1 system has been described previously [Vamanu et al., 2012, 2013]. In in vitro tests control means the samples taken after simulation from the restored microbiota without any treatment.

\section{Microbiological analyses}

Analyses were undertaken by serial dilution. Colony number was determined by an automated colony counter (colonyQuant; schuett-biotec, Göttingen Germany) with the corresponding software [Mitsuyama \& Sata, 2008; Rossi et al., 2005; Vamanu et al., 2013].

Total number of anaerobes and facultative anaerobes was determined using anaerobe agar and nutrient agar: MacConkey agar for coliforms; azide blood agar base for enterococci; sulfite polymyxin sulfadiazine agar for clostridia; Rogosa agar for lactobacilli; bifidus selective medium agar for bifidobacteria. Media were purchased from Oxoid (Hampshire, UK) and Sigma-Aldrich (St. Louis, MO, USA) [Vamanu et al., 2013].

\section{Relative quantification of bacteria number}

Microbial dynamic analyses of beneficial microorganisms (Lactobacillus species and Bifidobacterium species) from the human colon were carried out by reverse transcription-polymerase chain reaction (RT-PCR). Two-milliliters of each sample taken from the GIS1 system were centrifuged at $1,000 \times \mathrm{g}$ for $5 \mathrm{~min}$ at room temperature and the sediments were washed thrice with a sterile phosphate buffer. The sediments were used for DNA extraction with an innuPREP Stool DNA kit (AJ Innuscreen, Berlin, Germany). DNA concen- tration was determined using NanoVue ${ }^{\mathrm{TM}}$ Plus (GE Healthcare, Chicago, IL, USA), and indicated that the extracts were pure and sufficiently concentrated for PCR. Before RT-PCR, primer efficiency was obtained using standard curves at DNA concentrations of $10 \mathrm{ng}$ to $1 \mathrm{pg}$ in a PCR with primer concentrations of $0.1-0.5 \mu \mathrm{mol}$. Primer efficiency was calculated using the formula:

$$
\text { Primer efficiency }(\%)=-1+10(-1 / \text { slope })
$$

For gene quantification, a SYBR ${ }^{\circledR}$ Green RT-PCR Master Mix kit (Applied Biosystems, Foster City, CA, USA) was used according to manufacturer instructions. For each reaction, $50 \mathrm{ng}$ of DNA and $0.2-0.5 \mu \mathrm{mol}$ of each primer were introduced. Samples were run using a 7900 real-time PCR system (Applied Biosystems) and each reaction was done in triplicate. After amplification, results were generated by RQMan-

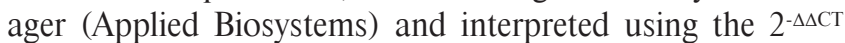
method [Mai et al., 2013; Qin et al., 2003; Wang et al., 2013].

\section{Statistical analyses}

The methods chosen were focused on the rigor and on quality of data interpretation. All parameters for antimicrobial and antioxidant activities were assessed in triplicate and results were expressed as mean $\pm \mathrm{SD}$. Statistical analyses were carried out using GraphPad Prism v6.0 (GraphPad, San Diego, CA, USA). Differences were considered significant at $p \leq 0.05$. Correlation between antioxidant levels and bacteria number were calculated using the EXCEL program from Microsoft Office 2010 package.

\section{RESULTS}

\section{Antioxidant effects of mushroom mycelia}

Variations in the antioxidant status in parts of the human colon are due exclusively to the fermentation processes of microorganisms in microbiota in the digestive tract [Koleva et al., 2015]. The total antioxidant activity of the formulation based on lyophilized mycelia of $P$. ostreatus and $L$. edodes is shown in Figure 1 (FRAP method) and Figure 2 (ABTS method). Both assays were conducted and presented simultaneously to compare results after mycelia ingestion. For the ascending colon, administration of fresh mycelia of $L$. edodes generated the maximum FRAP of $17.1 \pm 0.12 \mathrm{mmol} / \mathrm{mL}$ dry extract, which was $6.43 \%$ higher than that for administration of lyophilized mycelia of $P$. ostreatus species. In general, the highest FRAP was for the ascending colon rather than the transverse colon. Values for the antioxidant effect were higher upon administration of the lyophilized product MycoPo, which were $14.11 \%$ higher than those for L. edodes mycelia, and $38.82 \%$ higher than those of A. brunnescens. The maximum FRAP was $17 \pm 0.5 \mathrm{mmol}$, and MycoPo was the only sample that caused an increase in the FRAP in this region compared with the baseline control. In the descending colon, a decrease in the antioxidant effect was observed for all samples. A significant $(p<0.01)$ decrease of $42.46 \%$ was noted after administration of the fresh mycelia of $L$. edodes. Consumption of $A$. brunnescens had a similar effect, but the reducing antioxidant power decreased by $23.07 \%$. 


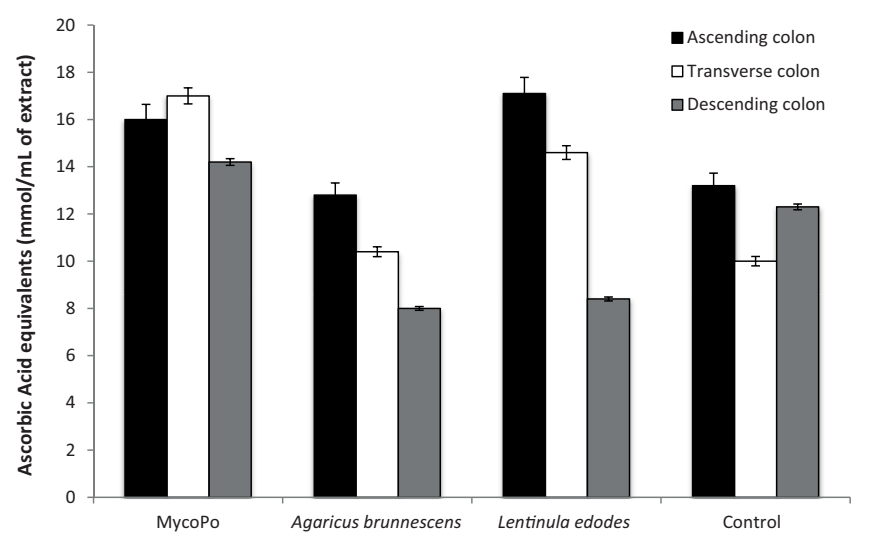

FIGURE 1. Reducing power in the simulated colonic segments. Results were significantly different at $p<0.05$.

Determination of the total antioxidant capacity using the ABTS method showed the highest value of $17.1 \pm 0.07 \mathrm{mmol}$ upon administration of L. edodes mycelia. This value was approximately $8 \%$ higher compared with the value on administration of the lyophilized product of $P$. ostreatus. The transverse colon was an exception because MycoPo administration caused an increase in the total antioxidant capacity by $14.11 \%$ compared with the effect of $L$. edodes mycelia. In segments of the descending colon, $L$. edodes mycelia had a maximum effect of $18.3 \pm 0.15 \%$. Consumption of $A$. brunnescens resulted in the lowest values of the total antioxidant capacity, which decreased by an average of $20 \%$ when passing from one region of the colon to another.

\section{Polyphenol status of colon regions}

Polyphenol content was correlated with the antioxidant status and microbial composition of microbiota. The total polyphenolic content was higher after the consumption of A. brunnescens, particularly in the transverse and descending regions of the colon. In the ascending colon, the three samples contained a similar amount of polyphenolic compounds, with differences of $\approx 3 \%$. Administration of the MycoPo product resulted in similar total polyphenolic content in all colonic regions (though an increase in total polyphenolic content in the final region was observed for all samples). The largest increase was recorded after administration of L. edodes mycelia (33.2 $\pm 1.4 \mathrm{mg}$ gallic acid/g of product) (Table 1$)$.

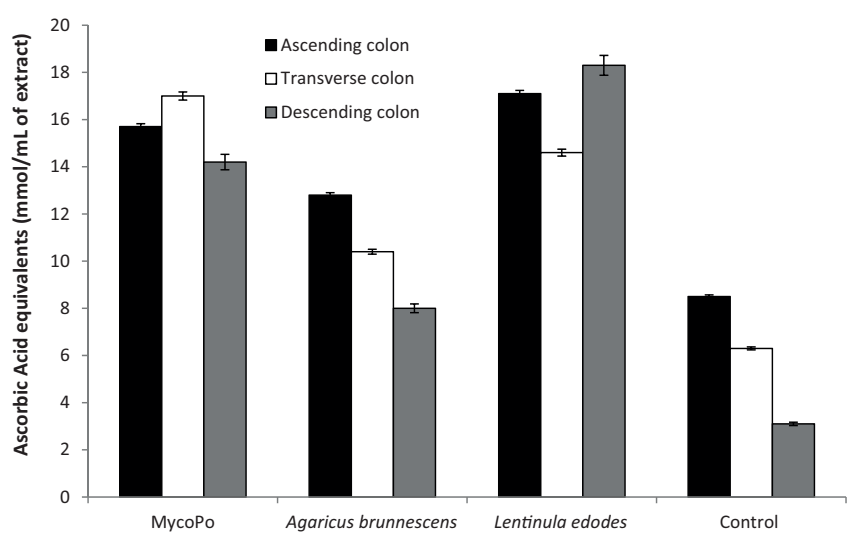

FIGURE 2. ABTS radical scavenging activity in the simulated colonic segments. Results were significantly different at $p<0.05$.

The total flavonoid content showed maximum values after the consumption of $A$. brunnescens. They increased by an average of $19 \%$ when passing from one colonic region to another, reaching $3.5 \mathrm{mg}$ quercetin/g mushroom consumed in the terminal segment. Direct administration of mycelia (lyophilized or fresh) showed a reduction in the median segment of the colon of $5-10 \%$.

After simulation in the GIS1 system, four types of polyphenols were identified by HPLC. The major phenolic acids were gentisic acid and homogentisic acid. Caffeic acid was identified in small amounts in all simulated regions and for all three samples. The minimum quantity was identified in the ascending colon after administration of mycelia of L. edodes $(0.026 \mathrm{mg} / 100 \mathrm{~mL})$. Gallic acid was identified only in the ascending segment $(0.018 \mathrm{mg} / 100 \mathrm{~mL})$ after the consumption of $A$. brunnescens (Table 1).

\section{Microbiological analyses in simulated colon}

The GIS1 system provides the opportunity to understand the impact of consumption/administration of a mushroom product has on favorable microbial strains and on potentially pathogenic microbial strains [Guerra et al., 2012]. Administration of mycelia of $L$. edodes caused a significant $(\mathrm{p}<0.02)$ increase in the number of anaerobic microorganisms in transverse and descending regions of the colon. The number of lactobacilli decreased in the final region of the colon to $5.81 \pm 2.65 \mathrm{CFU} / \mathrm{mL}$ (Table 2). Use of the lyophilized product MycoPo resulted in a relatively constant number of favorable

TABLE 1. Quantity of polyphenol carboxylic acids $(\mathrm{mg} / 100 \mathrm{~mL})$ in the simulated colonic segments.

\begin{tabular}{|c|c|c|c|c|c|c|c|c|c|c|c|c|}
\hline \multirow[b]{2}{*}{ Samples } & \multicolumn{4}{|c|}{ Ascending colon } & \multicolumn{4}{|c|}{ Transverse colon } & \multicolumn{4}{|c|}{ Descending colon } \\
\hline & $\begin{array}{l}\text { Gallic } \\
\text { acid }\end{array}$ & $\begin{array}{l}\text { Homo- } \\
\text { gentisic } \\
\text { acid }\end{array}$ & $\begin{array}{c}\text { Gentisic } \\
\text { acid }\end{array}$ & $\begin{array}{l}\text { Caffeic } \\
\text { acid }\end{array}$ & $\begin{array}{l}\text { Gallic } \\
\text { acid }\end{array}$ & $\begin{array}{l}\text { Homo- } \\
\text { gentisic } \\
\text { acid }\end{array}$ & $\begin{array}{l}\text { Gentisic } \\
\text { acid }\end{array}$ & $\begin{array}{l}\text { Caffeic } \\
\text { acid }\end{array}$ & $\begin{array}{l}\text { Gallic } \\
\text { acid }\end{array}$ & $\begin{array}{l}\text { Homo- } \\
\text { gentisic } \\
\text { acid }\end{array}$ & $\begin{array}{l}\text { Gentisic } \\
\text { acid }\end{array}$ & $\begin{array}{l}\text { Caffeic } \\
\text { acid }\end{array}$ \\
\hline MycoPo & - & $\begin{array}{c}0.114 \\
\pm 0.001\end{array}$ & $\begin{array}{c}1.041 \\
\pm 0.02^{* *}\end{array}$ & $\begin{array}{l}0.042 \\
\pm 0.02\end{array}$ & - & - & $\begin{array}{c}0.866 \\
\pm 0.001^{*}\end{array}$ & $\begin{array}{l}0.035 \\
\pm 0.02\end{array}$ & - & $\begin{array}{l}0.157 \\
\pm 0.02\end{array}$ & $\begin{array}{c}1.433 \\
\pm 0.01^{*}\end{array}$ & $\begin{array}{c}0.04 \\
\pm 0.001\end{array}$ \\
\hline Agaricus brunnescens & $\begin{array}{l}0.018 \\
\pm 0.001\end{array}$ & $\begin{array}{l}0.058 \\
\pm 0.01\end{array}$ & $\begin{aligned} & 1.452 \\
\pm & 0.005^{* *}\end{aligned}$ & $\begin{array}{c}0.031 \\
\pm 0.003\end{array}$ & - & - & $\begin{array}{l}1.116 \\
\pm 0.10^{*}\end{array}$ & $\begin{array}{l}0.033 \\
\pm 0.01\end{array}$ & - & $\begin{array}{l}0.179 \\
\pm 0.04\end{array}$ & $\begin{array}{l}1.132 \\
\pm 0.02^{*}\end{array}$ & $\begin{array}{c}0.033 \\
\pm 0.005\end{array}$ \\
\hline $\begin{array}{l}\text { Freeze-dried mycelium } \\
\text { Lentinula edodes }\end{array}$ & - & $\begin{array}{c}0.099 \\
\pm 0.003 \\
\end{array}$ & - & $\begin{array}{c}0.026 \\
\pm 0.001 \\
\end{array}$ & - & - & - & $\begin{array}{l}0.029 \\
\pm 0.01 \\
\end{array}$ & - & $\begin{array}{l}0.089 \\
\pm 0.02\end{array}$ & $\begin{array}{l}0.367 \\
\pm 0.03\end{array}$ & $\begin{array}{c}0.03 \\
\pm 0.02 \\
\end{array}$ \\
\hline
\end{tabular}

Results were significantly different at $* \mathrm{p}<0.05$ and ${ }^{* *} \mathrm{p}<0.01$. 
TABLE 2. Average number of microorganisms $(\log \mathrm{CFU} / \mathrm{mL}$ ) for the different microbial groups.

\begin{tabular}{|c|c|c|c|c|}
\hline Bacterial group & Product & Ascending colon & Transverse colon & Descending colon \\
\hline $\begin{array}{l}\text { Total anaerobes } \\
\text { Facultative anaerobes } \\
\text { Lactobacilli } \\
\text { Bifidobacteria } \\
\text { Enterococci } \\
\text { Clostridia } \\
\text { Coliforms } \\
\end{array}$ & MycoPo & $\begin{array}{l}7.19 \pm 1.00 \\
6.56 \pm 0.01 \\
6.68 \pm 0.80 \\
6.91 \pm 0.01 \\
6.55 \pm 2.56 \\
6.47 \pm 1.60 \\
5.02 \pm 1.36\end{array}$ & $\begin{array}{l}6.92 \pm 0.50 \\
6.11 \pm 0.25 \\
7.00 \pm 0.62^{*} \\
7.00 \pm 0.05^{*} \\
6.79 \pm 1.85 \\
6.15 \pm 1.02 \\
7.33 \pm 0.26 \\
\end{array}$ & $\begin{array}{l}6.38 \pm 1.55 \\
4.49 \pm 1.41 \\
6.75 \pm 0.27 \\
6.92 \pm 0.18 \\
6.68 \pm 3.67 \\
6.08 \pm 2.42 \\
7.39 \pm 0.71\end{array}$ \\
\hline $\begin{array}{l}\text { Total anaerobes } \\
\text { Facultative anaerobes } \\
\text { Lactobacilli } \\
\text { Bifidobacteria } \\
\text { Enterococci } \\
\text { Clostridia } \\
\text { Coliforms } \\
\end{array}$ & Agaricus brunnescens & $\begin{array}{l}7.09 \pm 1.00 \\
6.75 \pm 0.50 \\
6.99 \pm 1.02 \\
6.79 \pm 0.63 \\
7.32 \pm 1.15 \\
6.55 \pm 1.65 \\
7.42 \pm 1.21^{*} \\
\end{array}$ & $\begin{array}{l}7.41 \pm 1.41 \\
7.23 \pm 1.08 \\
7.40 \pm 0.71^{* *} \\
6.83 \pm 1.25 \\
7.42 \pm 0.44 \\
6.49 \pm 0.42 \\
6.73 \pm 1.08 \\
\end{array}$ & $\begin{array}{l}7.28 \pm 0.88 \\
7.09 \pm 1.45 \\
7.26 \pm 0.05^{* *} \\
7.06 \pm 1.06 \\
6.92 \pm 1.65 \\
6.51 \pm 1.38 \\
7.12 \pm 1.35 \\
\end{array}$ \\
\hline $\begin{array}{l}\text { Total anaerobes } \\
\text { Facultative anaerobes } \\
\text { Lactobacilli } \\
\text { Bifidobacteria } \\
\text { Enterococci } \\
\text { Clostridia } \\
\text { Coliforms }\end{array}$ & $\begin{array}{l}\text { Freeze-dried mycelium } \\
\text { Lentinula edodes }\end{array}$ & $\begin{array}{l}7.69 \pm 1.43 \\
7.40 \pm 0.46 \\
6.69 \pm 1.43 \\
7.04 \pm 0.90 \\
7.71 \pm 1.56 \\
6.68 \pm 0.32 \\
7.19 \pm 0.81\end{array}$ & $\begin{array}{l}7.88 \pm 1.01 \\
7.26 \pm 0.85 \\
6.94 \pm 1.80 \\
7.19 \pm 0.67^{*} \\
7.26 \pm 1.11 \\
6.61 \pm 0.74 \\
7.24 \pm 1.65\end{array}$ & $\begin{array}{l}7.85 \pm 1.29 \\
7.49 \pm 1.34 \\
5.81 \pm 2.65 \\
6.68 \pm 0.68 \\
7.00 \pm 0.66 \\
6.63 \pm 0.76 \\
7.27 \pm 1.00\end{array}$ \\
\hline
\end{tabular}

Results were significantly different at ${ }^{*} \mathrm{p}<0.05$ and ${ }^{* *} \mathrm{p}<0.01$.

microbiota in intermediate and final regions of the colon. MycoPo administration induced a decrease in the number of coliform microorganisms in the ascending colon $(\approx 2 \mathrm{CFU} / \mathrm{mL})$ compared with the control samples.

Using RT-PCR (Table 3), we determined the ratio of the three groups of microorganism species, Lactobacillus, Bifidobacterium and Enterobacteriaceae, after consumption/administration of mushrooms. We noted an increase in the number of lactobacilli in the transverse colon in samples treated with MycoPo and A. brunnescens. With regard to the population of Bifidobacteria species after consumption of $A$. brunnescens, there was a slight increase in the descending colon whereas, in the rest of the colon regions, the number of Bifidobacteria species was lower. In the samples in which the mycelia of $L$. edodes were administered, a decrease in the number of Lactobacillus and Bifidobacteria species was noted in all three parts of the colon. The population of Enterobacteriaceae species varied greatly between the three parts of the colon. There was a significant $(\mathrm{p}<0.01)$ increase in the number of cells after consumption of $A$. brunnescens, especially in the descending colon. The only sample in which the number of enterobacteriaceae was lower compared with the control was the sample in which MycoPo was administered: the transverse colon.

\section{DISCUSSION}

Our in vitro study showed active molecules released through digestion in the stomach and duodenum but especially due to the fermentation action of colonic microbiota. Mushrooms are subject to the action of microbiota, so they release biologically-active molecules gradually. This phenomenon is reflected through the different antioxidant status between the three main parts of the human colon. We did not include the gastroduodenal-digestion phase because mycelia were embedded in enterosoluble capsules, which provides resistance to the actions of lysozyme, pepsin, bile salts, pancreatin and acid $\mathrm{pH}$. The capsule disintegrates within $10 \mathrm{~min}$ of introduction into the environment, which simulates the first part of the colon. Thus, it has been found to have a considerable impact on patients who had developed (or are at high risk of developing) diseases associated

TABLE 3. Microbial dynamics analysis using RT-PCR technique.

\begin{tabular}{|c|c|c|c|}
\hline \multirow{2}{*}{ Samples } & \multicolumn{3}{|c|}{$2^{-\Delta \Delta C t}$ values* } \\
\hline & Lactobacillus & Bifidobacterium & Enterobacteriaceae \\
\hline AC Control & 1.00 & 1.00 & 1.00 \\
\hline TC Control & 1.00 & 1.00 & 1.00 \\
\hline DC Control & 1.00 & 1.00 & 1.00 \\
\hline AC MycoPo & 1.04 & 0.16 & 1.93 \\
\hline TC MycoPo & 3.28 & 0.07 & 0.23 \\
\hline DC MycoPo & 0.58 & 0.06 & 3.23 \\
\hline $\begin{array}{l}\mathrm{AC} \\
\text { A. brunnescens }\end{array}$ & 0.56 & 0.06 & $1100.33^{*}$ \\
\hline $\begin{array}{l}\mathrm{TC} \\
\text { A. brunnescens }\end{array}$ & 1.54 & 0.54 & $1307.81^{*}$ \\
\hline $\begin{array}{l}\text { DC } \\
\text { A. brunnescens }\end{array}$ & 0.28 & 1.44 & $87526.27^{*}$ \\
\hline AC L. edodes & 0.00 & 0.06 & 128.76 \\
\hline TC L. edodes & 0.00 & 0.07 & 23.57 \\
\hline DC L. edodes & 0.00 & 0.13 & 371.99 \\
\hline
\end{tabular}

Results were significantly different at $* p<0.05$ and $* * p<0.01$.

*value above 1 represents an increase of bacteria number; $\mathrm{AC}$ - ascending colon; TC - transverse colon; DC - descendent colon. 
TABLE 4. Correlation between antioxidant levels and favorable microbial strains.

\begin{tabular}{l|c|c|c|c}
\hline & Lactobacilli & Bifidobacteria & $\begin{array}{c}\text { Reducing } \\
\text { power }\end{array}$ & $\begin{array}{c}\text { ABTS } \\
\text { radical } \\
\text { scavenging } \\
\text { activity }\end{array}$ \\
\hline $\begin{array}{l}\text { ABTS } \\
\text { scavenging } \\
\text { activity }\end{array}$ & 0.872 & 0.868 & 0.760 & - \\
$\begin{array}{l}\text { Reducing } \\
\text { power }\end{array}$ & 0.726 & 0.864 & - & \\
$\begin{array}{l}\text { Bifidobacteria } \\
\text { Lactobacilli }\end{array}$ & 0.750 & - & & \\
\hline
\end{tabular}

with oxidative stress (e.g., diabetes mellitus, cardiovascular diseases) [Hutcheson \& Rocic, 2012]. Several studies have demonstrated the positive effects of antioxidant administration, but correlation of antioxidant status with the capacity to modulate human colonic microbiota has not been studied.

In the present study, the antioxidant status and microbiota population were highly correlated. Consumption of $A$. brunnescens and ingestion of MycoPo was highly correlated with favorable microbial strains $\left(R^{2}>0.7\right.$ - Table 4$)$. For $L$. edodes mycelia, antioxidant status was similar to that for MycoPo ingestion, but was not directly correlated with Lactobacillus and Bifidobacterium strains. In this situation, polyphenol carboxylic acids from colon segments were no more abundant (Table 2) and were expected to be bound with polysaccharide molecules. Bioavailability of MycoPo and A. brunnescens was higher and degree of correlation was relatively constant from the one colon region to another. These results showed the direct effect of phenolic fractions on the viability of favorable microbial strains during in vitro tests.

It has been shown that glucans in P. ostreatus can induce stimulation of microbial strains beneficial to health in the human digestive tract. These glucans have a prebiotic function but, until now, those data have not been supported by in vitro tests simulating the complex relationship between different microbial strains [Synytsya et al., 2009]. In vitro studies using simulation systems cannot show the accumulation of active molecules in colonic cells or the fermentation function of microbiota causing partial degradation, which has a direct effect on the absorption capacity of biologically-active compounds. Also, reductions in antioxidant status are due to changes suffered by phenolic components from the fermentation activity of microbiota or an alkaline $\mathrm{pH}$, which is more pronounced in the ascending colon [Rodriguez-Roque et al., 2013]. The significant $(\mathrm{p}<0.01)$ loss of the total antioxidant activity observed after $A$. brunnescens consumption in the descending colon was due to the reduced capacity to release biologically-active compounds from this mushroom. Compared with the use of products based on the mycelia of $P$. ostreatus and L. edodes, the decrease was about $58 \%$ and $67 \%$.

These data are in accordance with studies based on thermal processing of mushrooms. Direct use of P. ostreatus, including mycelia, is preferable because nutritional properties remain intact. Hydration restores much of the nutritional value and enables bioactive compounds to be released if sufficient water is provided [Lam \& Okello, 2015].

There are differences between the biological values of sporocarps and mycelia. The latter do not accumulate a large amount of metal ions that could elicit biological effects. The presence of iron decreases the antioxidant potential expressed in terms of iron chelation and radical scavenging [Yokota et al., 2016]. Use of mushroom mycelia can elicit rapid antioxidant effects due to a greater accessibility of bioactive compounds [Vamanu et al., 2013].

We noted variations in phenolic acid content that could be explained by the fermentation action of microbiota. We hypothesize that a major portion of the polyphenols released by digestion in the stomach (low $\mathrm{pH}$ ) and in the small intestine (enzymatic attack and bile acids) was absorbed (in vivo) or degraded by microbiota in the ascending colon. Quantities of phenolic acids can differ considerably depending on sample processing [Lam \& Okello, 2015, Prasad et al., 2015]. Direct consumption of $A$. brunnescens mushrooms and administration of the lyophilized product MycoPo maintained a considerable level of gentisic acid and a relatively constant amount of caffeic acid (Table 1). The fermentation action of microbiota aided the ability to release antioxidant molecules, which accumulated in the descending colon. The present study demonstrated that gentisic acid and caffeic acid were not necessarily the only acids to be released, but they were the most stable. Other acids could have undergone hydrolysis and conformational changes, but they were not identified. The same phenomenon could also be attributed to flavonoids, which have been associated with mushrooms (e.g., catechin, rutin, quercetin, myricetin) [Vamanu \& Nita, 2014].

Studies have shown that consumption of the dried sporocarps of $P$. ostreatus leads to an increase in the antioxidant status in the colon (i.e., release of compounds with antioxidant effects). These effects have concurred with the use of the mycelia of the same species (MycoPo) but not with consumption of wild species. The latter cannot sustain constant antioxidant status in all regions of the colon due to rapid release of these compounds [Vamanu et al., 2013]. Even if there were differences in the type of MycoPo, antioxidant status would have been reduced from a region to another region of the colon (Figure 1,2). We showed that the consumption of mushrooms with medicinal properties (e.g., L. edodes) had a more pronounced effect in the final part of the colon. However, we noted a reduction in the quantity of bioactive compounds in the final part of the colon compared with other parts of the colon. Severe diseases of the colon (e.g., cancer) usually occur in this part, so a reduction in the quantity of bioactive compounds in this region will increase the risk of such diseases.

Differences calculated between favorable microbial strains were interpreted as a response to the quantity and composition of antioxidant molecules. These observations were also confirmed by the significant $(\mathrm{p}<0.01)$ correlation of antioxidant status in the transverse and descending parts of the colon after administration of the lyophilized product MycoPo and consumption of $A$. brunnescens with the number of Lactobacillus and Bifidobacteria species $\left(R^{2}>0.85\right)$. The low degree of correlation upon direct administration of fresh mycelia 
was due to the reduced capacity of fermentation processes in the colon to release molecules with biological activity.

The present study highlighted the capacity of lyophilized mushroom mycelia to control the microbiological structure of microbiota. The proportion of microbial strains could be controlled by administration of these products, and could elicit important responses to metabolic/cardiovascular diseases. This approach is a natural and non-toxic way to control the number of pathogenic strains and metabolic activity of favorable strains, and could be part of "tailored therapy". These aspects are important for the bioavailability of bioactive compounds because differences between different regions of the colon were noted in the present study. The time of residence is different for different bioactive compounds, which influences fermentation and metabolic capacities, which have direct effects on microbiota modulation and well-being [Gerritsen et al., 2011].

The present study had limitations. We did not ascertain correlation between in vitro and in vivo administration but contaminants would affect (at least in part) the results. Also, the physiological status of each individual has an important role [Hur et al., 2011]. In addition, we would not have been able to eliminate the interaction between exogenous factors and physiological mechanisms of the body [Guerra et al., 2012].

\section{CONCLUSIONS}

Effects of administration of a functional product containing the lyophilized mycelia of $P$. ostreatus compared with that of the lyophilized mycelia of $L$. edodes and consumption of $A$. brunnescens represent a new approach in the mushroom mycelia valorization. A direct relationship between the presence of favorable bacterial strains and availability of bioactive compounds, with specificity for each region of the colon, was shown. The study has a significant biopharmaceutical implication on the improvement of colonic microbiota fingerprint. Ex vivo and/or in vitro studies in a dynamic simulator will be required to demonstrate the absorption capacity of bioactive compounds.

\section{ACKNOWLEDGEMENTS}

This work was supported by the Executive Agency for Higher Education, Research, Development and Innovation Funding - Human Resources, Theme 9/2010, PN-II-PT-PCCA-2011-3.1-0969/2012 and PN-II-RU-TE-2014-4-0061 (project 102/1.10.2015; www.robiomush.ro).

\section{CONFLICT OF INTEREST}

The authors declare that there is no conflict of interest regarding the publication of this paper.

\section{REFERENCES}

1. Alpinar K., Ozyurek M., Kolak U., Guclu K., Aras C., Altun M., Celik S.E., Berker K.I., Bektasoglu B., Apak R., Antioxidant capacities of some food plants wildly grown in Ayvalik of Turkey. Food Sci. Technol. Res., 2009, 15, 59-64.
2. Bartosch S., Fite A., Macfarlane G.T., McMurdo E.T., Characterization of bacterial communities in feces from healthy elderly volunteers and hospitalized elderly patients by using real-time PCR and effects of antibiotic treatment on the fecal microbiota. Appl. Environ. Microbiol., 2004, 70, 3575-3581.

3. Chen S.Y., Ho K.J., Liang C.H., Tsai C.H., Huang L.Y., Mau J.L., Preparation of culinary-medicinal king oyster mushroom Pleurotus eryngii-fermented products with high ergothioneine content and their taste quality. Int. J. Med. Mush., 2012, 14, 85-93.

4. Choi C.H., Chang S.K., Alteration of gut microbiota and efficacy of probiotics in functional constipation. J. Neurogastroenterol. Motil., 2015, 21, 4-7.

5. Conlon M.A., Bird A.R., The impact of diet and lifestyle on gut microbiota and human health. Nutrients, 2015, 7, 17-44.

6. Din A.R.J.M., Razak S.A., Sabaratnam V., Effect of mushroom supplementation as a prebiotic compound in super worm based diet on growth performance of red tilapia fingerlings. Sains Malaysiana, 2012, 41, 1197-1203.

7. Diwan R., Shinde A., Malpathak N., Phytochemical composition and antioxidant potential of Ruta graveolens L. in vitro culture lines. J. Bot., 2012, Article ID 685427.

8. Ekor M., The growing use of herbal medicines: issues relating to adverse reactions and challenges in monitoring safety. Front. Pharmacol., 2014, 4, 177.

9. Elisashvili V., Submerged cultivation of medicinal mushrooms: bioprocesses and products (review). Int. J. Med. Mush., 2012, 14, 211-239.

10. Green R.J., Murphy A.S., Schulz B., Watkins B.A., Ferruzzi M.G., Common tea formulations modulate in vitro digestive recovery of green tea catechins. Mol. Nutr. Food Res., 2007, 51, 1152-1162.

11. Guerra A., Etienne-Mesmin L., Livrelli V., Denis S., Blanquet-Diot S., Alric M., Relevance and challenges in modeling human gastric and small intestinal digestion. Trends Biotechnol., 2012, 30, 591-600.

12. Gerritsen J., Smidt H., Rijkers G.T., de Vos W.M., Intestinal microbiota in human health and disease: the impact of probiotics. Genes Nutr., 2011, 6, 209-240.

13. Hamer H.M., Jonkers D., Venema K., Vanhoutvin S., Troost F.J., Brummer R.J., Review article: the role of butyrate on colonic function. Aliment. Pharmacol. Therapeut., 2008, 27, 104-119.

14. Heilig H.G., Zoetendal E.G., Vaughan E.E., Marteau P., Akkermans A.D., de Vos W.M., Molecular diversity of Lactobacillus spp. and other lactic acid bacteria in the human intestine as determined by specific amplification of 16 S ribosomal DNA. Appl. Environ. Microbiol., 2002, 68, 114-123.

15. Hughes R., Magee E.A.M., Bingham S., Protein degradation in the large intestine: relevance to colorectal cancer. Curr. Issues Intest. Microbiol., 2000, 1, 51-58.

16. Hur S.J., Lim B.O., Decker E.A., McClements D.J., In vitro human digestion models for food applications. Food Chem., 2011, 125, 1-12.

17. Hutcheson R., Rocic P., The metabolic syndrome, oxidative stress, environment, and cardiovascular disease: the great exploration. Exp. Diabetes Res., 2012, Article ID 271028.

18. Jeong S.C., Koyyalamudi S.R., Hughes J., Khoo C., Bailey T., Marripudi K., Park J.P., Kim J.H., Song C.H., Antioxidant and immunomodulating activities of exo- and endopolysac- 
charide fractions from submerged mycelia cultures of culinarymedicinal mushrooms. Int. J. Med. Mush., 2013, 15, 251-266.

19. Kailasapathy K., Chin, J., Survival and therapeutic potential of probiotic organisms with reference to Lactobacillus acidophilus and Bifidobacterium spp.. Immun. Cell Biol., 2000, 78, 80-88.

20. Koleva P.T., Bridgman S.L., Kozyrskyj A.L., The infant gut microbiome: evidence for obesity risk and dietary intervention. Nutrients, 2015, 7, 2237-2260.

21. Lam Y.S., Okello E.J., Determination of lovastatin, -glucan, total polyphenols, and antioxidant activity in raw and processed oyster culinary-medicinal mushroom, Pleurotus ostreatus (higher Basidiomycetes). Int. J. Med. Mush., 2015, 17, 117-128.

22. Lee B.C., Bae J.T., Pyo H.B., Choe T.B., Sang W.K., Hwang H.J., Yun J.W., Submerged culture conditions for the production of mycelial biomass and exopolysaccharides by the edible Basidiomycete Grifola frondosa. Enz. Microbial Technol., 2004, 35, 369-376.

23. Lindequist U., Niedermeyer T.H.J., Jülich W.D., The pharmacological potential of mushrooms. Evid. Based Complement Alt. Med., 2005, 2, 285-299.

24. Mai V., Torrazza R.M., Ukhanova M., Wang X., Sun Y., Li N., Shuster J., Sharma R., Hudak M.L., Neu J., Distortions in development of intestinal microbiota associated with late onset sepsis in preterm infants. PLOS One, 2013, 8, e52876.

25. Manach C., Scalbert A., Morand C., Remesy C., Jimenez L., Polyphenols: food sources and bioavailability. Am. J. Clin. Nutr., 2004, 79, 5727-5747.

26. Mitsuyama K., Sata M., Gut microflora: a new target for therapeutic approaches in inflammatory bowel disease. Expert Opin. Ther. Tar., 2008, 12, 301-312.

27. Ozyurek M., Bener M., Guclu K., Donmez A.A., Suzgec-Selcuk S., Pirildar S., Mericli A.H., Apak R., Evaluation of antioxidant activity of Crataegus species collected from different regions of Turkey. Rec. Nat. Prod., 2012, 6, 263-277.

28. Prasad R., Varshney V.K., Harsh N.S., Kumar M., Antioxidant capacity and total phenolics content of the fruiting bodies and submerged cultured mycelia of sixteen higher Basidiomycetes mushrooms from India. Int. J. Med. Mush., 2015, 17, 933-941.

29. Premanath R., Sudisha J., Devi L.N., Aradhya S.M.. Antibacterial and anti-oxidant activities of fenugreek (Trigonella foenum graecum L.) leaves. J. Med. Plants Res., 2011, 5, 695-705 [http:// docsdrive.com/pdfs/academicjournals/rjmp/2011/695-705.pdf].

30. Qin X., Emerson J., Stapp J., Stapp L., Abe, P., Burns J.L., Use of real-time PCR with multiple targets to identify Pseudomonas aeruginosa and other nonfermenting gram-negative bacilli from patients with cystic fibrosis. J. Clin. Microbiol., 2003, 41, 4312-4317.

31. Rinttila T., Kassinen A., Malinen E., Krogius L., Palva A., Development of an extensive set of $16 \mathrm{~S}$ rDNA-targeted primers for quantification of pathogenic and indigenous bacteria in faecal samples by real-time PCR. J. Appl. Microbiol., 2004, 97, 1166-1177.
32. Rodriguez-Roque M.J., Rojas-Grau M.A., Elez-Martinez P., Martin-Belloso O., Soymilk phenolic compounds, isoflavones and antioxidant activity as affected by in vitro gastrointestinal digestion. Food Chem., 2013, 136, 206-212.

33. Rossi M., Corradini C., Amaretti A., Nicolini M., Pompei A., Zanoni S., Matteuzzi D., Fermentation of fructooligosaccharides and inulin by bifidobacteria: a comparative study of pure and fecal cultures. Appl. Environ. Microbiol., 2005, 71, 6150-6158.

34. Synytsya A., Mickova K., Synytsya A., Jablonsky I., Spevacek J., Erban V., Kovarikova E., Copikova J., Glucans from fruit bodies of cultivated mushrooms Pleurotus ostreatus and Pleurotus eryngii: structure and potential prebiotic activity. Carbohydr. Pol., 2009, 76, 548-556.

35. Tzortzis G., Goulas A.K., Gee J.M., Gibson G.R., Novel galactooligosaccharide mixture increases the bifidobacterial population numbers in a continuous in vitro fermentation system and in the proximal colonic contents of pigs in vivo. J. Nutr., 2005, 135, 1726-1731.

36. Vamanu E., Biological activities of the polysaccharides produced in submerged culture of two edible Pleurotus ostreatus mushrooms. J. Biomed. Biotechnol., 2012, Article ID 565974.

37. Vamanu E., Nita S., Biological activity of fluidized bed ethanol extracts from several edible mushrooms. Food Sci. Biotechnol., 2014, 23, 1483-1490.

38. Vamanu E., Pelinescu D., Avram I., Niță S., Vamanu A., Study of PROBAC product influence on infant microbiota in a single chamber colonic fermentation model GIS1. Ann. Microbiol., 2012, 63, 1029-1038.

39. Vamanu E., Pelinescu D., Avram I., Nita S., An in-vitro evaluation of antioxidant and colonic microbial profile levels following mushroom consumption. BioMed Res. Int., 2013, Article ID 289821.

40. van de Heijning B.J.M., Berton A., Bouritius H., Goulet O., GI symptoms in infants are a potential target for fermented infant milk formulae: a review. Nutrients, 2014, 6, 3942-3967.

41. Wasser S.P., Medicinal mushroom science: Current perspectives, advances, evidences, and challenges. Biomed. J., 2014, 37, 345-356.

42. Wang Y., Ametaj B.N., Ambrose D.J., Gänzle M.G., Characterisation of the bacterial microbiota of the vagina of dairy cows and isolation of pediocin-producing Pediococcus acidilactici. BMC Microbiol., 2013, 13, 19.

43. Yokota M.E., Frison P.S., Marcante R.C., Jorge L.F., Valle J.S., Dragunski D.C., Colauto N.B., Linde G.A., Iron translocation in Pleurotus ostreatus basidiocarps: production, bioavailability, and antioxidant activity. Gen. Mol. Res., 2016, 15, Art. no. UNSP 1501788 .

Submitted: 2 August 2016. Revised: 11 November and 9 December 2016. Accepted: 3 January 2017. Published on-line: 21 April 2017. 